\title{
Miniscrew-assisted rapid palatal expansion (MARPE) protocols applied in different ages and stages of maturation of the midpalatal suture: cases report
}

Protocolos de expansão rápida palatina assistida por mini-implantes (MARPE) aplicados em diferentes idades e estágios de maturação da sutura palatina mediana: relato de casos Protocolos de expansión rápida palatina asistida por mini tornillos (MARPE) aplicados a diferentes edades y etapas de maduración de la sutura palatina media: reporte de casos

Marcelo de Melo Quintela ORCID: https://orcid.org/0000-0003-0818-8493 Universidade Metropolitana de Santos, Brazil Universidade de Santo Amaro, Brazil E-mail: marceloquintela@com.br

Sabrina Buchmann Rossi ORCID: https://orcid.org/0000-0002-0210-938X Universidade Metropolitana de Santos, Brazil E-mail: sarossi@uol.com.br

Katty Lalangui Vera

ORCID: https://orcid.org/0000-0002-6796-4256 Universidade Metropolitana de Santos, Brazil E-mail: kattylalangui@gmail.com

Jaime Cordova Peralta

ORCID: https://orcid.org/0000-0002-5935-3279 Universidade Metropolitana de Santos, Brazil E-mail: jaimecordovaperalta@gmail.com

Isaias Donizeti Silva

ORCID: https://orcid.org/0000-0001-6335-7785

Universidade de Santo Amaro, Brazil

E-mail: isaiasdonizeti@gmail.com

Letícia Alecrim de Souza

ORCID: https://orcid.org/0000-0002-3663-7746

Universidade Metropolitana de Santos, Brazil

E-mail: souzalee@yahoo.com

Caio Vinícius Gonçalves Roman-Torres ORCID: https://orcid.org/0000-0001-9864-6894 Universidade de Santo Amaro, Brazil E-mail: cvgrt@hotmail.com

Heloísa Fonseca Marao ORCID: https://orcid.org/0000-0002-6128-8576 Universidade de Santo Amaro, Brazil E-mail: heloisafonsecamarao@yahoo.com.br

Wilson Roberto Sendyk ORCID: https://orcid.org/0000-0002-3742-1330 Universidade de Santo Amaro, Brazil E-mail: wsendyk@prof.unisa.br

Angélica Castro Pimentel ORCID: https://orcid.org/0000-0002-6317-6439 Universidade de Santo Amaro, Brazil E-mail: draangelicacp@uol.com.br

\begin{abstract}
Objective: To evaluate the Microimplant-assisted Rapid Palatal Expansion (MARPE), considered an alternative to surgical interventions for disjunction of the midpalatal suture in adolescent patients and young adults with maxillary transverse deficiency. The stage of ossification of the midpalatal suture, bone quality and adequate activation protocols are factors that can influence the quantity and quality of the orthopedic separation. Methodology: This paper demonstrates the application of MARPE in an unfavorable case report, of an adult patient with total crossbite, in an advanced stage of fusion of the palatine and maxillary processes, with poverty in the posterior bone volume, in comparison with the same therapy in an adolescent at an earlier stage of sutural maturation. In both cases, after
\end{abstract}


tomographic examinations and oral scanning, the installations and recommended activation protocol were performed. These were not sufficient in the case of the adult patient, and generated side effects that, to be overcome, required changes in activations and additional maneuvers. Results: The application of MARPE may require clinical versatility to adopt differentiated protocols in relation to chronological age, bone thickness and sutural ossification stage. Conclusion: In the end, new computer tomography scans and a clinical examination showed satisfactory results in both patients. In the unfavorable case, the opening of the midpalatal suture occurred at more modest levels, but it was sufficient to correct the posterior crossbite.

Keywords: Palatal expansion technique; Orthodontic anchorage procedures; Transverse maxillary atresia; Microimplant-assisted rapid palatal expansion; Case report.

\section{Resumo}

Objetivo: Avaliar a Expansão Palatal Rápida Assistida por Microimplantes (MARPE), considerada uma alternativa às intervenções cirúrgicas para disjunção da sutura palatina mediana em pacientes adolescentes e adultos jovens com deficiência transversa maxilar. O estágio de ossificação da sutura palatina mediana, a qualidade óssea e os protocolos de ativação adequados são fatores que podem influenciar na quantidade e na qualidade da separação ortopédica. Metodologia: Este trabalho demonstra a aplicação do MARPE em um relato de caso desfavorável, de uma paciente adulta com mordida cruzada total, em estágio avançado de fusão dos processos palatino e maxilar, com pobreza no volume ósseo posterior, em comparação com a mesma terapia em uma adolescente em um estágio anterior de maturação sutural. Em ambos os casos, após os exames tomográficos e escaneamento oral, foram realizados as instalações e o protocolo de ativação recomendado. Isso não foi suficiente no caso do paciente adulto e gerou efeitos colaterais que, para serem superados, exigiram mudanças nas ativações e manobras adicionais. Resultados: A aplicação do MARPE pode exigir versatilidade clínica para adoção de protocolos diferenciados em relação à idade cronológica, espessura óssea e estágio de ossificação sutural. Conclusão: Ao final, novas tomografias computadorizadas e exame clínico mostraram resultados satisfatórios em ambos os pacientes. No caso desfavorável, a abertura da sutura palatina mediana ocorreu em níveis mais modestos, mas foi suficiente para corrigir a mordida cruzada posterior.

Palavras-chaves: Técnica de expansão palatina; Procedimentos de ancoragem ortodôntica; Mordida Cruzada; Expansão palatal rápida assistida por microimplante; Maxila; Relato de caso.

\section{Resumen}

Objetivo: evaluar la expansión palatina rápida asistida por microimplantes (MARPE), considerada una alternativa a las intervenciones quirúrgicas para la disyunción de la sutura palatina media en pacientes adolescentes y adultos jóvenes con deficiencia transversal maxilar. El estadio de osificación de la sutura mediopalatina, la calidad ósea y los protocolos de activación adecuados son factores que pueden influir en la cantidad y calidad de la separación ortopédica. Metodología: Este trabajo demuestra la aplicación de MARPE en un reporte de caso desfavorable de un paciente adulto con mordida cruzada total, en etapa avanzada de fusión de los procesos palatino y maxilar, con pobre volumen óseo posterior, en comparación con la misma terapia en un adolescente de una etapa más temprana de maduración de la sutura. En ambos casos, tras la TC y la exploración oral, se realizaron las instalaciones y el protocolo de activación recomendado. Esto no fue suficiente en el caso del paciente adulto y generó efectos secundarios que, para ser superados, requirieron cambios en las activaciones y maniobras adicionales. Resultados: La aplicación de MARPE puede requerir versatilidad clínica para adoptar protocolos diferenciados con relación a la edad cronológica, grosor óseo y estadio de osificación de la sutura. Conclusión: Al final, la nueva tomografía computarizada y el examen clínico mostraron resultados satisfactorios en ambos pacientes. En el caso desfavorable, la apertura de la sutura mediopalatina se produjo a niveles más modestos, pero fue suficiente para corregir la mordida cruzada posterior.

Palabras clave: Técnica de expansión palatina; Procedimientos de anclaje ortodóntico; Mordida Cruzada; Expansión palatina rápida asistida por microimplantes; Maxila; Reporte de un caso.

\section{Introduction}

Rapid maxillary expansion (RME) has proven protocols with a high success rate when applied to children with maxillary transverse deficiency. On the other hand, when the pubertal outbreak is reached, with the maturation of the suture ossification, the success of RME becomes unpredictable. In young people and adults, disjunction therapy has been more effective through surgical assistance, to avoid excessive inclination of the supporting dental elements and/or their root resorption, in addition to dehiscences and fenestrations (Gurgel, 2019; Lee et al, 2010; Choi et al, 2016).

In order to prevent such undesirable effects and optimize the expansion potential in different ages and maturation stages, MARPE (miniscrew-assisted rapid palatal expander) emerged. In this device, four miniscrews are usually installed in 
the paramedian region of the palatal suture. They are produced with titanium alloy grade 5. To choose the position of the screws, careful planning with Cone Bean Computed Tomography (CBCT) of the palate region is important, so that he best bone thickness is chosen for bicortical anchorage, favoring success in the stability of miniscrews (Gurgel, 2019).

MARPE was introduced in a South Korean article that described the clinical case of an adult patient in which RME anchored in miniscrews prevented surgical disjunction (Lee et al, 2010). Sequentially, the expansion stability with MARPE was evaluated in 69 adult patients, with a maximum age of 28 years (Choi et al, 2016). With a success rate of $86.9 \%$, the researchers stated that the failure in some patients was unclear, but it could be related to the differences in the mineralization process of the midpalatal suture.

Since then, it is assumed that the advanced maturation process of the palatal suture has been an obstacle to therapeutic success with MARPE. As a complicating factor, it is known that chronological age is not a reliable parameter for predicting suture maturation (Korbmacher et al, 2007).

The midpalatal suture morphology was classified in tomographic images of 140 individuals, between 5 and 58 years old, in stages A, B, C, D and E by Angelieri et al. (2013). Stages A and B were present up to 13 years of age. Stage C was found in individuals aged 11 to 17 years. Complete fusion of the palatal area (stage D) and also the maxillary area (stage E) was found after 11 years of age in girls. Stage D could already be seen in $23 \%$ of the boys aged between 14 and 17 years.

This article presents two case reports that exemplify the behavior of MARPE in different age groups and in different stages of sutural ossification. The complications and the means of obtaining success in the application of clinical protocols of activations are described, as well as the procedures that can be incorporated into our practice when dealing with transversal jaw deficiency through MARPE.

\section{Methodology}

The cases reports are a research method that uses qualitative data, collected from real events, to explore themes inserted in its own context, in this case the clinical application of a rapid maxillary expansion device, the MARPE, and its nuances clinical, both in performance and in side effects.

\subsection{Ethical Considerations}

Respecting the ethical principles of the Declaration of Helsinki (1964), which govern research with human beings, this work was submitted to the Ethics and Research Committee of the Universidade Metropolitana de Santos, São Paulo (Brazil) under the approval number 4.732.849, and the patients signed the term of free and informed consent for the treatment and its inclusion in scientific work.

\subsection{Case Description 1}

A 14-year-old girl was brought to the Postgraduate Clinic of the Dentistry College of Universidade Metropolitana de Santos (UNIMES) with complaints related to posterior crossbite, having already obtained indication from a professional for future orthognathic surgery.

The clinical examination revealed a facial pattern III with dolichofacial growth and mostly mouth breathing. The frontal analysis showed some characteristics that suggested sagittal deficiency of the maxilla, such as: tegumentary stretching, relative enlargement of the lower third of the face, narrow and underdeveloped nostrils, a straight profile, without zygomatic projection, slightly open nasolabial angle, straight and unsupported base of nasal implantation for the nasal triangle and normal chin-neck line (Figures 1, 2 and 3). 
Figures 1: Extraoral photos from the front (A), profile (B) and smiling (C).
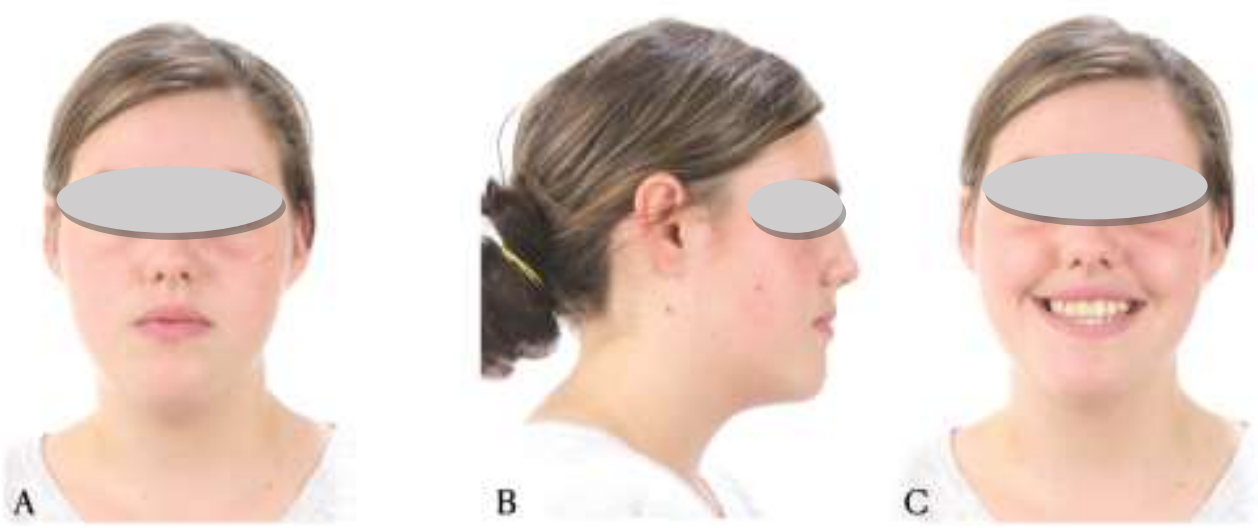

Source: Authors.

In intraoral analysis, total crossbite, anterior open bite, Class III in Angle's classification, maxillary atresia with ogival and deep palate, deviation of the lower right midline, as well as rotations and crowding in both arches were observed. The patient had gingivitis on the anterior teeth (Figures 2). The functional examination showed tongue interposition and atypical swallowing.

Figures 2: (A) Initial frontal, (B) right lateral, (C) left lateral, (D) upper occlusal and (E) lower occlusal views.

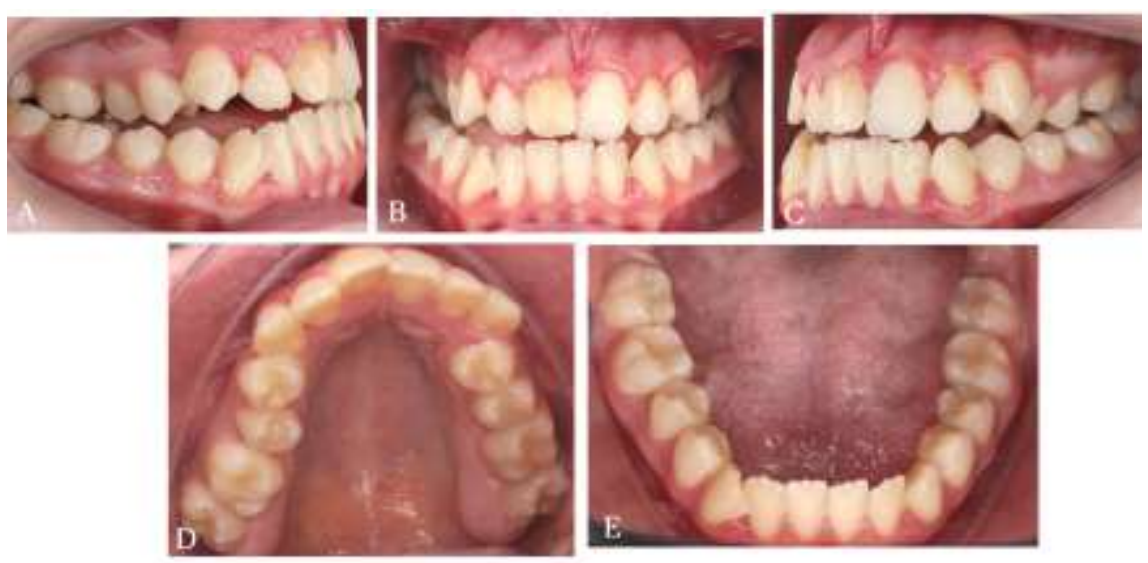

Source: Authors.

On the panoramic radiography, bone and periodontal normality, pneumatization of the maxillary sinuses and nasal turbinate hypertrophy were noted (Figure 3). 
Research, Society and Development, v. 10, n. 11, e503101119480, 2021

(CC BY 4.0) | ISSN 2525-3409 | DOI: http://dx.doi.org/10.33448/rsd-v10i11.19480

Figure 3: Initial panoramic radiography.

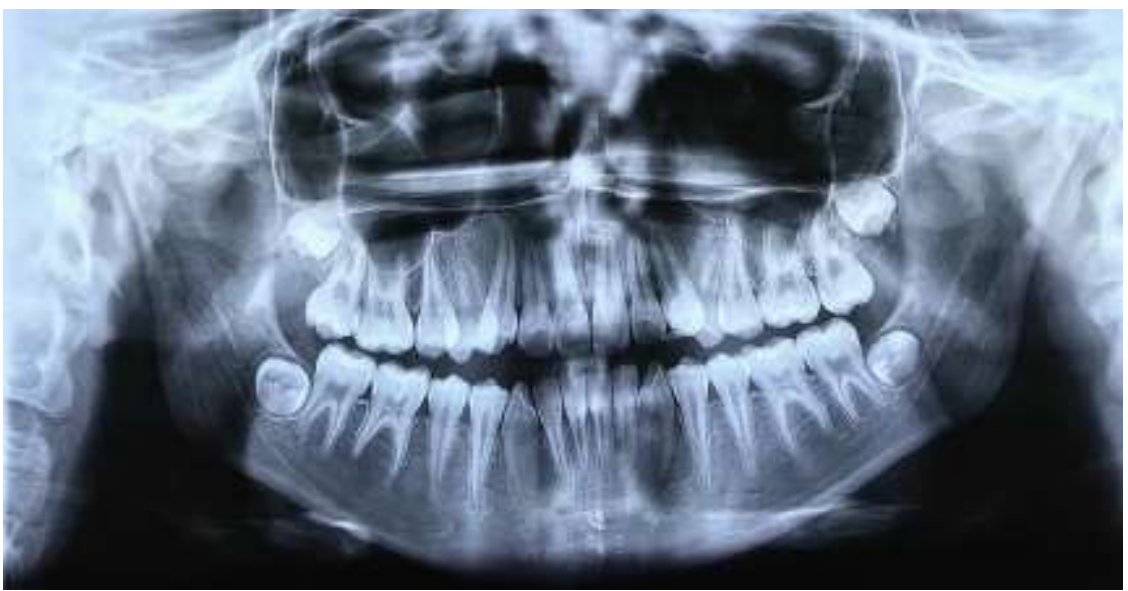

Source: Authors.

On lateral teleradiography (Figure 4), there was a divergent skeletal pattern of Class III $\left(\mathrm{ANB}=-2.64^{\circ}\right)(\mathrm{SN} . \mathrm{GoMe}=$ $\left.38.8^{\circ}\right)$, with sagittal underdevelopment of the maxilla $\left(\mathrm{Co}-\mathrm{A}=78.3^{\circ}\right)$, inclined upper incisors $\left(1 / . \mathrm{SN}=112.2^{\circ}\right)$ and retroclination of lower incisors $\left(/ 1 . \mathrm{NB}=19.1^{\circ}\right)$ and IMPA $=75.7^{\circ}$.

Figure 4: Teleradiography in lateral view.

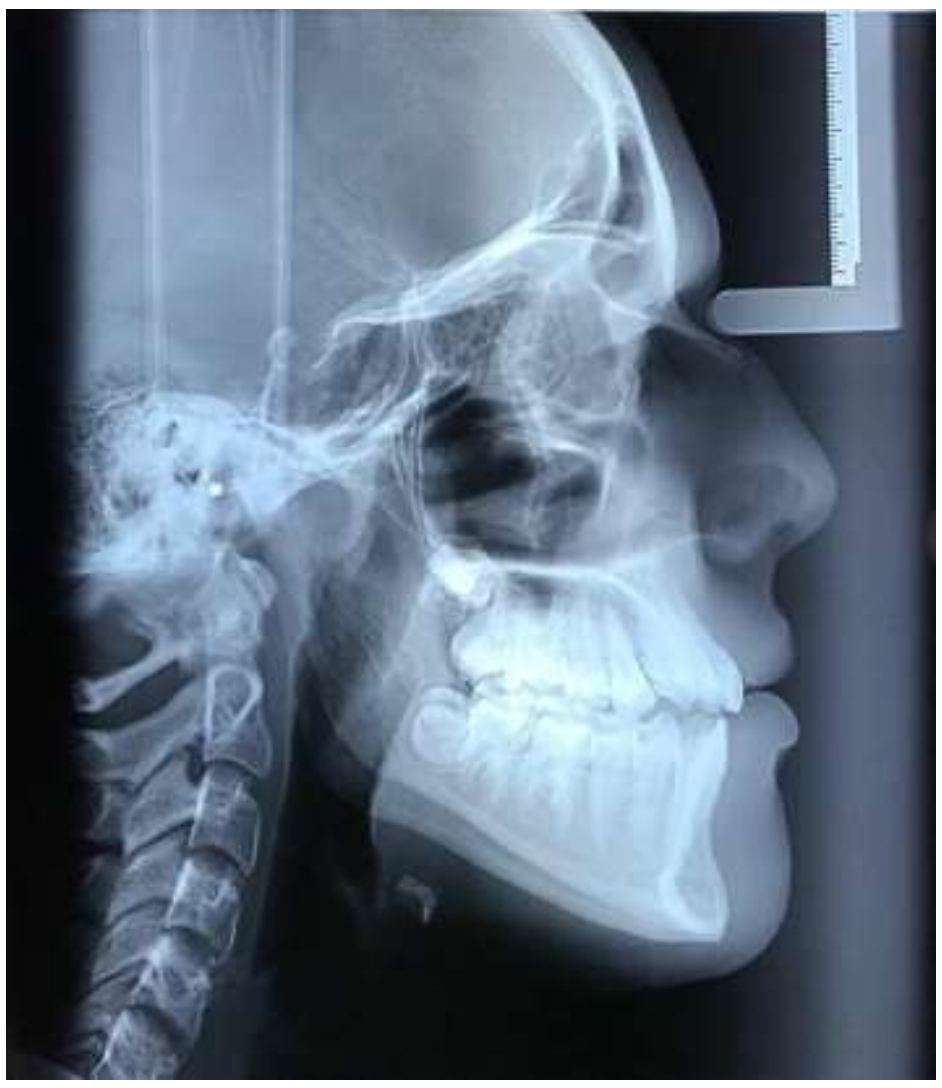

Source: Authors.

Evaluation of the maturation of the midpalatal suture in the maxillary CBCT indicated stage C of ossification, according to the Angelieri et al. (2013). 
The initial treatment objective was to correct the transverse deficiency of the maxilla. In the first phase, in the maxilla, a skeletal expansion should be performed by increasing the interdental distances to adjust its transverse relation. Then, dental compensation in the maxilla and mandible must be performed, through corrective orthodontic treatment, for sagittal and vertical correction aimed at obtaining the ideal occlusal relationship, function and facial harmony.

This device was chosen for the RME of the case described in spite of the literature maintaining the indication of conventional expansion, which was discarded after consulting the family explaining that, if the MARPE was successful, it could have less side effects on the teeth.

Areas of greater bone volume were chosen for the positioning of the insertion guides for orthodontic screws (Nojima et al, 2018), distal from 1st premolars and distal from 1st molars (Figure 5). Digital intraoral scanning was performed and after 3D printing of the model, MARPE was made with vestibular extensions for intra or extraoral elastics, to plan the sagittal displacement of the maxilla in a 2nd phase.

Figure 5: Initial $\mathrm{CBCT}$ of palate, indicating stage $\mathrm{C}$ of maturation in axial view; sagittal view indicating bone thickness; selection of the areas that cross the distal of the 1st premolars and 1st molars. In coronal view, areas were performed to select the miniscrews.

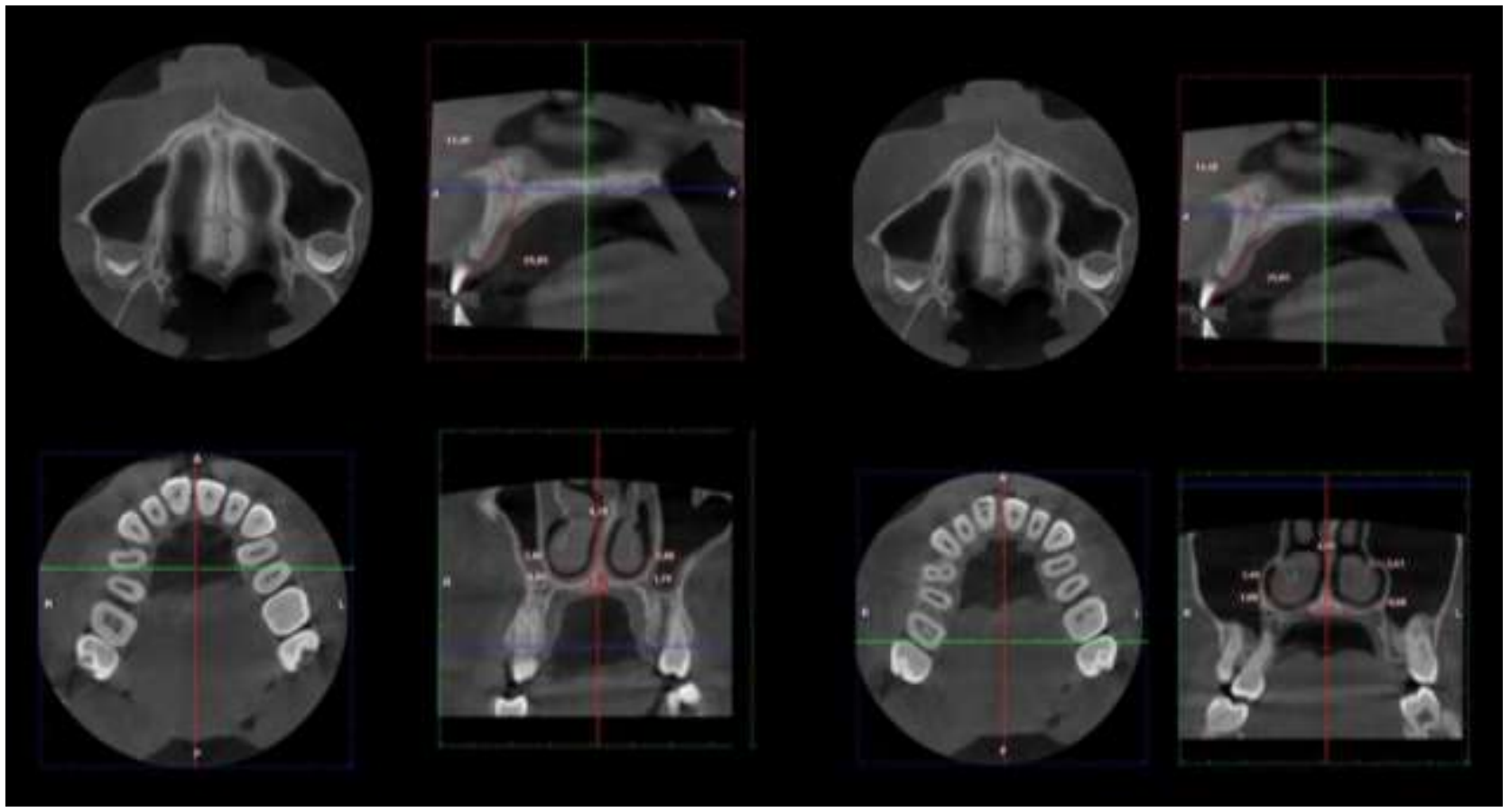

Source: Authors.

The model that was used was MARPE EX (Kika Ortodontia, Sorocaba, Brazil) with an opening of $11 \mathrm{~mm}$ and manufactured by PecLab® (Belo Horizonte, Brazil). The molar bands welded to the rods were cemented on the 1st molars with Ortho Bite resin $\left(\mathrm{FGM}^{\circledR}\right)$. Thus, the expander was positioned on the palate for insertion of miniscrews. Maintaining asepsis, the largest palatine nerves were bilaterally anesthetized and subperiosteal infiltrative anesthesia was applied to the mucosa points below the miniscrew insertion guides in MARPE., and 3\% mepivacaine was used with vasoconstrictor.

Milling was initiated by the guide holes (miniscrew passage slots) on the palate with the long $1.1 \mathrm{~mm}$ diameter orthodontic drill of the PecLab® Surgical Kit with a $4 \mathrm{~mm}$ deep hole, so we could avoid deviations during the insertion of the 
fixing screws. This site preparation was manually done with the contra-angle activated by the handpiece inserted in the micromotor fitting.

With a MARPE PecLab® insertion wrench attached to the contra-angle, the orthodontic screws were manually installed, alternately and crossing the positions. 02 anterior units (MARPE $1.8 \mathrm{~mm}$ long $\mathrm{x} 7 \mathrm{~mm}$ active tip $\mathrm{x} 4 \mathrm{~mm}$ transmucosal profile) and 02 posterior units (MARPE $1.8 \mathrm{~mm} \times 5 \mathrm{~mm} \times 4 \mathrm{~mm}$ ) were inserted. At this point, the contra-angle was replaced by the kit's surgical torquemeter and the $1.3 \mathrm{~mm}$ diameter square MARPE digital wrench reached the final torque of $35 \mathrm{~N} . \mathrm{cm}$

The protocol that was instituted was of one activation per day (1/4 turn). The patient reported that difficulties in speaking and eating were overcome in the first days. She did not report pain and did not need to use the prescribed analgesic medication (dipyrone monohydrate $500 \mathrm{mg}$ ). On the 14th day, it was possible to verify the clinical evidence of some disjunction due to the presence of an interincisive diastema, as shown in Figure 6. From then on, a complete lap was performed (4/4 laps) in office and she was oriented to perform two activations per day (1/4 morning and 1/4 night) at home for another 10 days, totaling $9.5 \mathrm{~mm}$ of the expander opening (Table 01), which was sufficient for wide expansion.

Figure 6: Occlusal view with newly installed MARPE(A) and after the 14 days of activation of MARPE (B).
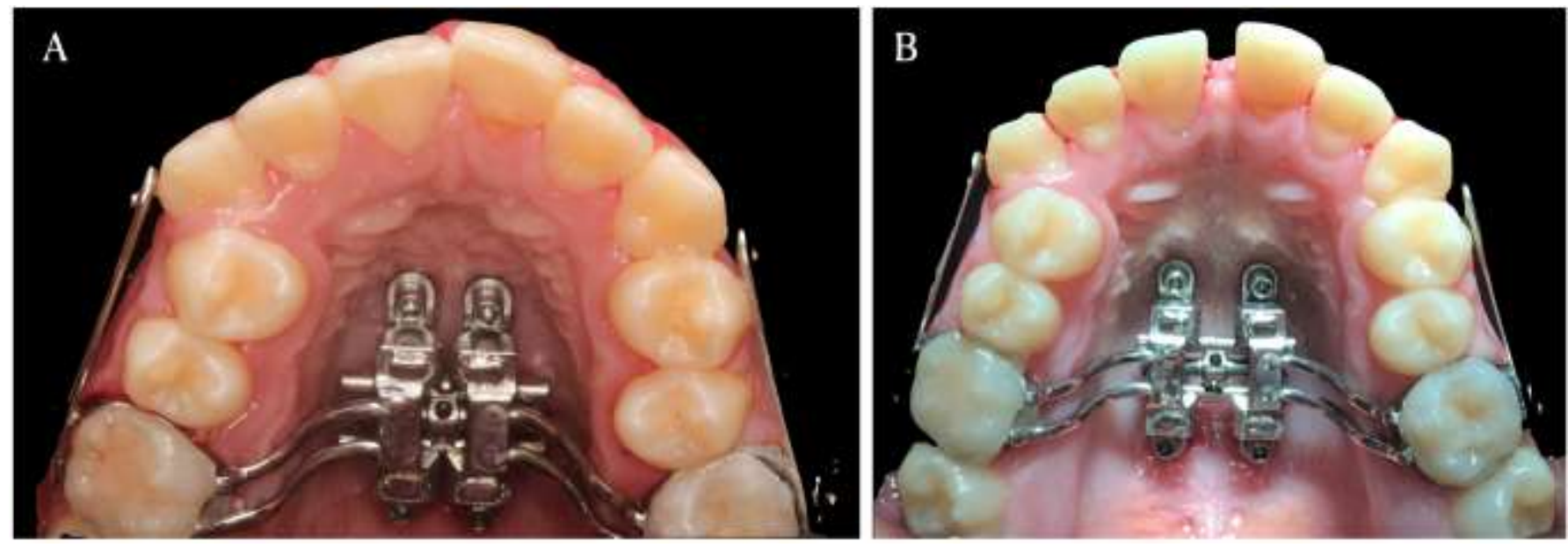

Source: Authors.

A new CBCT was requested, and a uniform maxillary disjunction was found in the axial and slightly triangular direction in the anteroposterior direction, with an opening of $4.6 \mathrm{~mm}$ in an area that corresponds to the distal first premolars (Figure 7). The tomography before and after MARPE show the disjunction of the midpalatal suture in frontal and occlusal views (Figure 8). Extra (Figure 9) and intraoral photos showed the success of the expansion (Figure 10).

The patient added that her breathing showed noticeable improvement, especially during physical activities. She spent 3 months with MARPE without any activation and was called to the consultation to start treatment with fixed braces. However, as gingivitis was still present, despite constant motivational guidelines, orthodontic installation was postponed, and she was accompanied for regular prophylaxis and biofilm control. 
Research, Society and Development, v. 10, n. 11, e503101119480, 2021

(CC BY 4.0) | ISSN 2525-3409 | DOI: http://dx.doi.org/10.33448/rsd-v10i11.19480

Figure 7: $\mathrm{CBCT}$ of the palate at the end of MARPE activations, with measurement of the opening in the distal areas of 1st premolars and mesial areas of 1st molars.

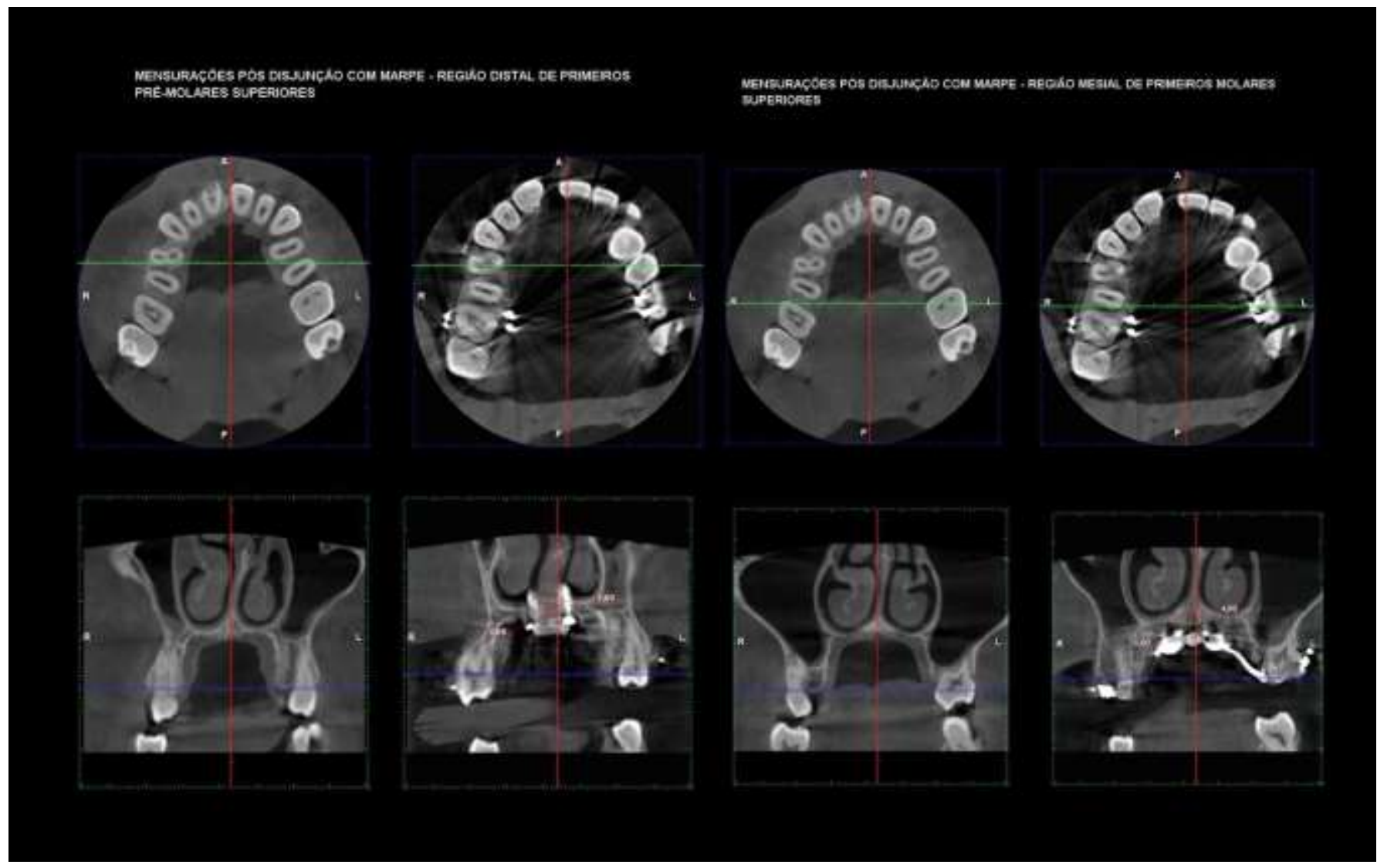

Source: Authors.

Figure 8: Computed tomography of the maxilla before and after MARPE, showing the disjunction of the midpalatal suture in frontal and occlusal views.

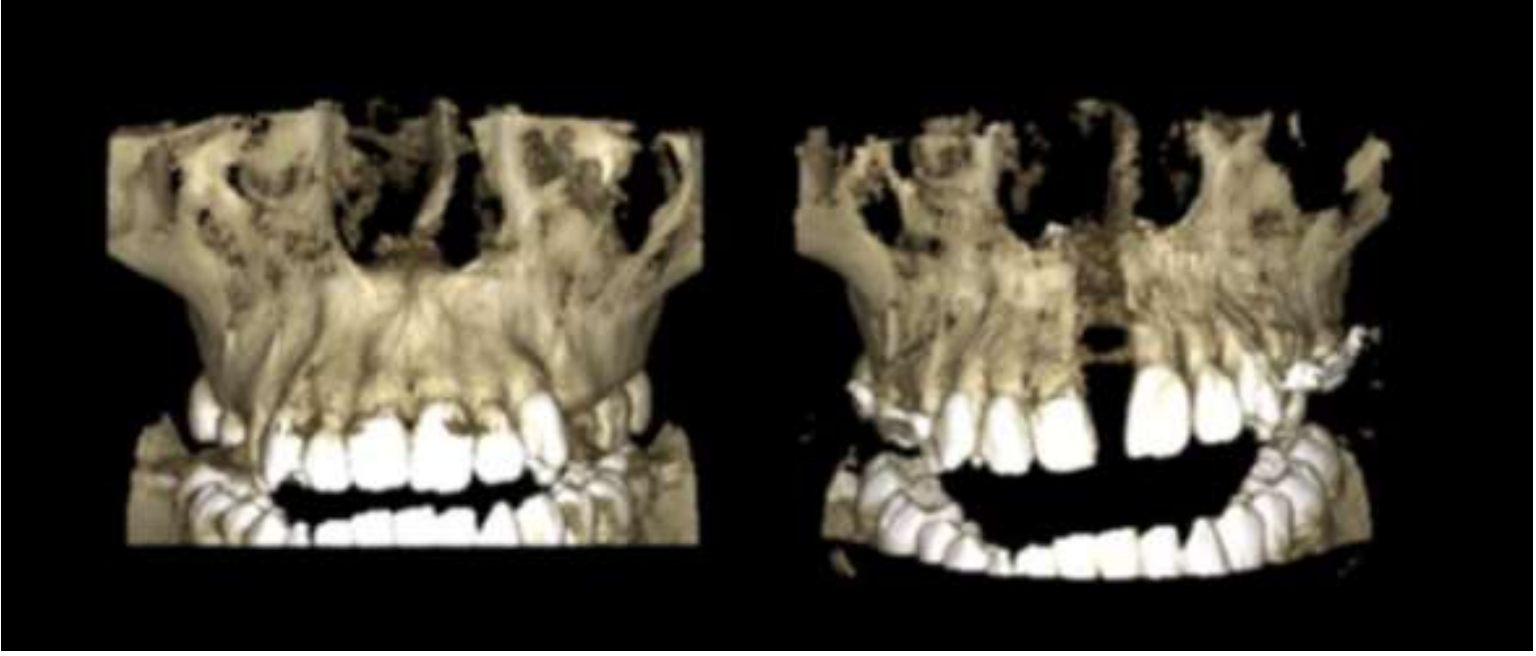

Source: Authors. 
Figure 9: Extraoral photos from the front, profile and smiling.
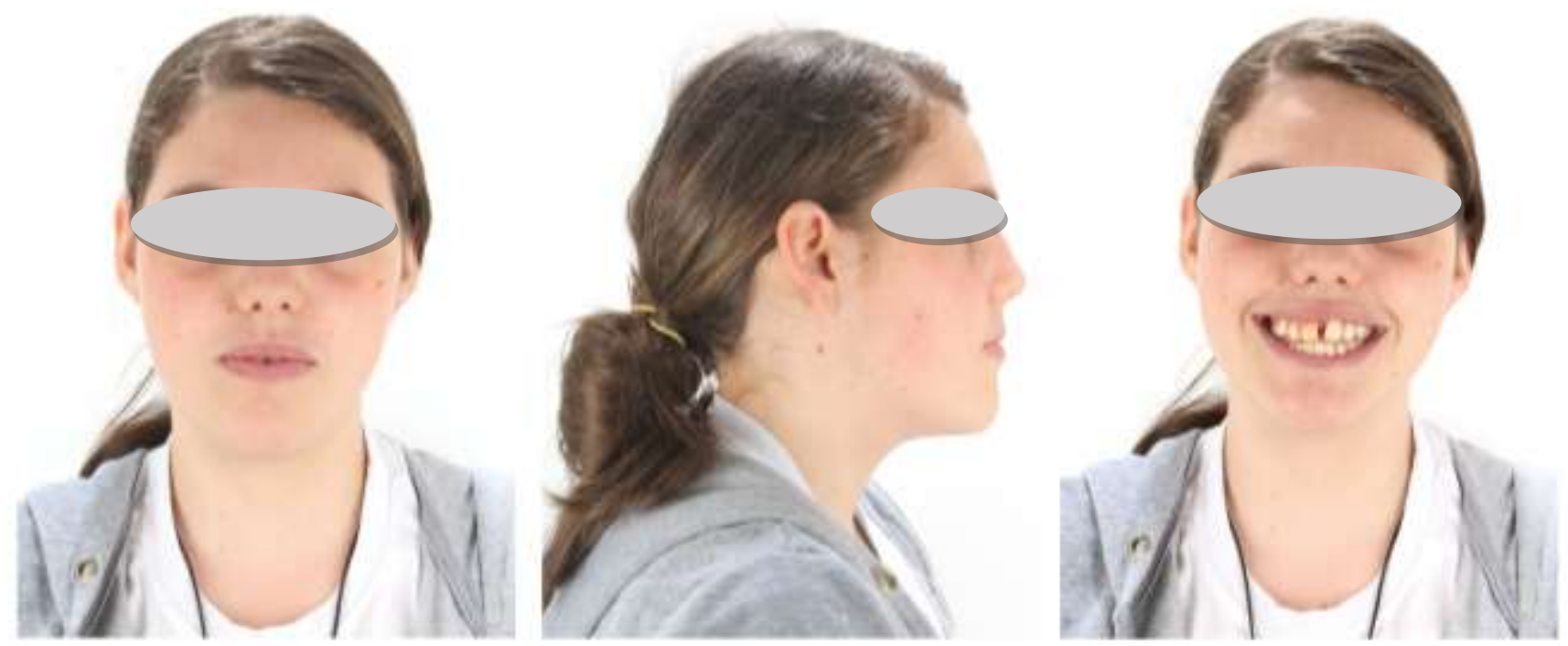

Source: Authors

Figure 10: (A) Final frontal intraoral photo, (B). Final right lateral intraoral photo, and (C). Final left lateral intraoral photo.
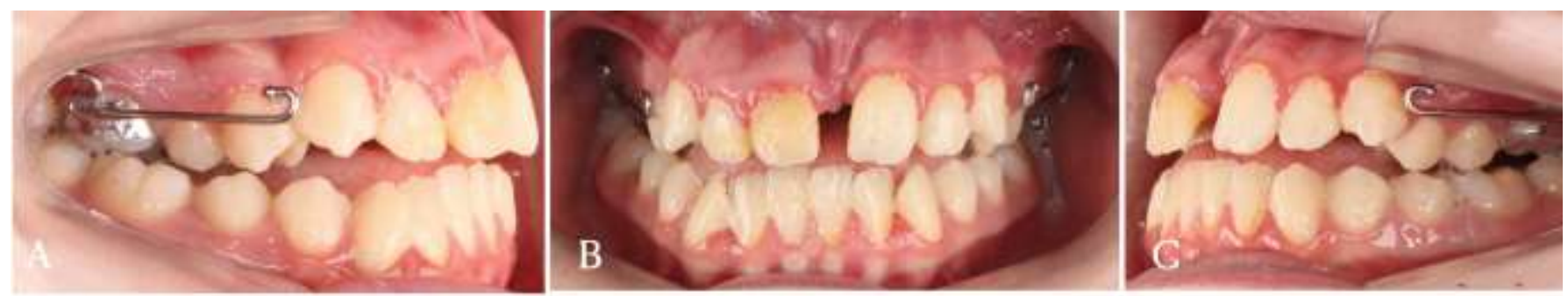

Source: Authors.

\subsection{Case Description 2}

A 31-year-old female was seen for orthodontic treatment at the Orthodontic Clinic of the Universidade Metropolitana de Santos (UNIMES), Brazil. Her main complaint was precisely her posterior crossbite, and she complained that since adolescence she had been seeking non-surgical treatment for her dentofacial condition, without success.

The patient presented a face III pattern, with dolichofacial growth. Subjective facial analysis confirmed the diagnosis as, in profile, facial concavity, little zygomatic projection, lack of support for the nasal triangle, slightly closed nasolabial angle and inverted labial relationship were observed. As the chin-neckline seemed normal, the discrepancy between the bone bases was exclusively related to sagittal maxilla deficiency. The frontal photos indicated a functional increase in the lower third of the face, with tegumentary stretching and difficulty with passive lip sealing (Figure 11). 
Research, Society and Development, v. 10, n. 11, e503101119480, 2021

(CC BY 4.0) | ISSN 2525-3409 | DOI: http://dx.doi.org/10.33448/rsd-v10i11.19480

Figure 11: Initial extraoral photographs from the front, profile and smiling.
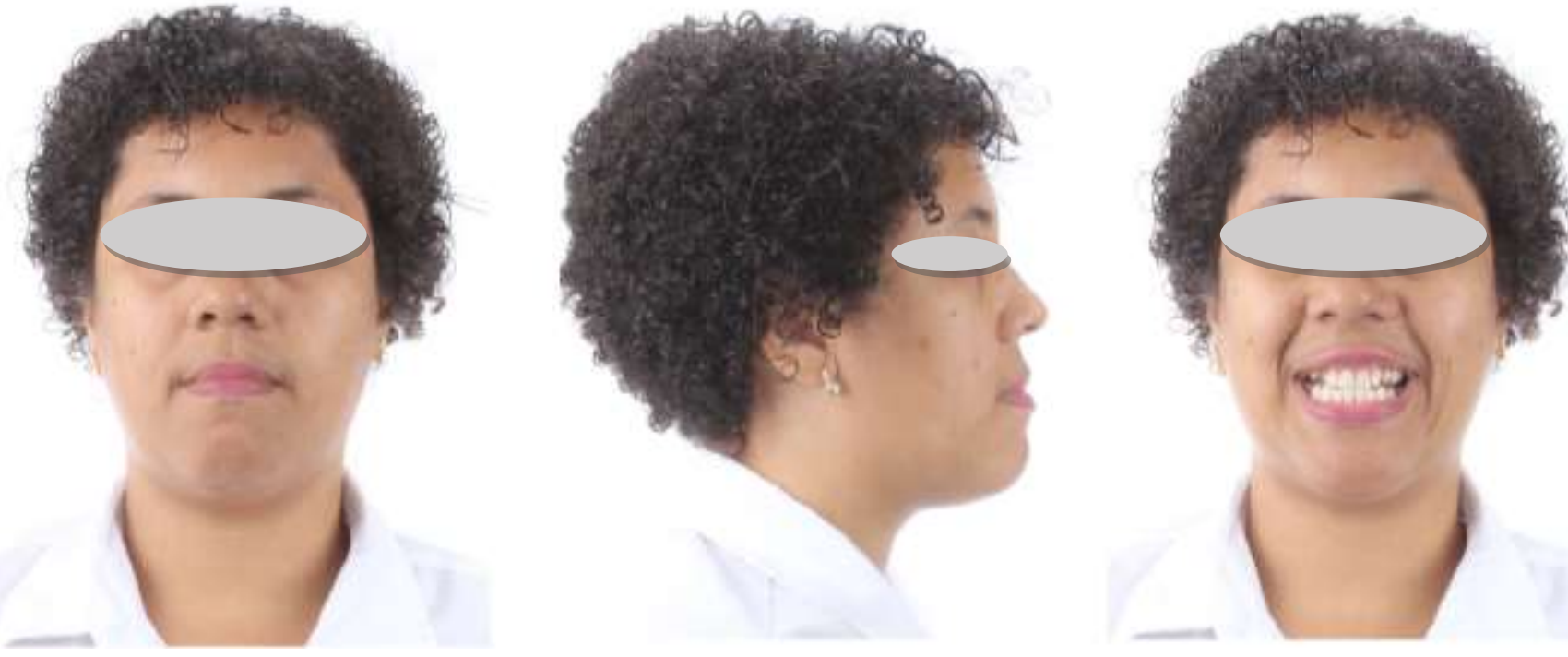

Source: Authors.

In the intraoral analysis, a total crossbite was found, with Angle Class III, maxillary atresia, prolonged retention of the 63 element in the arch and the palatine eruption of its successor. Crowds and gyroversions were present in the upper arch. The lower arch was expanded and with some dental alignment, except for the lingualization of the second premolars (Figure 12). In the functional examination, the patient's centric relation (CR) manipulation indicated an anterior top-to-top relationship, without any posterior contact.

Figures 12: Initial intraoral photographs from the front (A), right side (B), left side (C), upper occlusal (D) and lower occlusal (E) views.
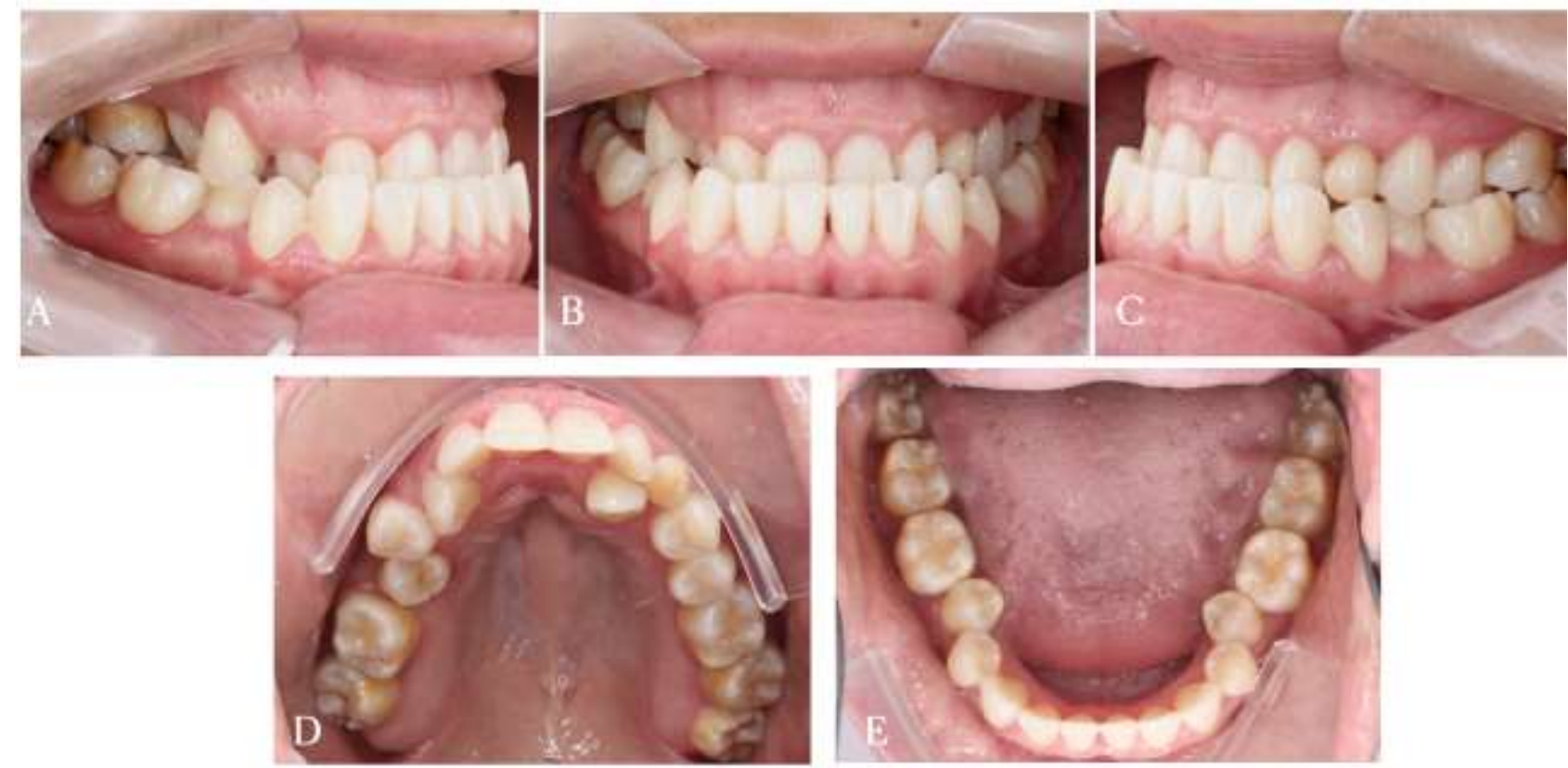

Source: Authors.

Panoramic radiography indicated bone and periodontal normality, with the retention of the 18 element, which was 
horizontalized and with its crown facing distal. The patient vehemently refused the recommendation to remove it, for fear of the surgical procedure. Cephalometric data indicated a slightly divergent skeletal pattern, with inclined upper incisors $(1 / . \mathrm{SN}=$ $\left.112.2^{\circ}\right)$ and lower incisor retroclination $\left(/ 1 . \mathrm{NB}=19.1^{\circ}\right)$ and IMPA $75.7^{\circ}$ (Figure 13$)$.

A CBTC of the maxilla was requested and the evaluation of the maturation of the midpalatal suture indicated stage D of ossification, when there are many fusion bridges in the maxillary bone, and complete palatal bone calcification, from the transverse palatal suture. The palate was asymmetrical and irregular, with slight deviated septum and very thin bone thickness in the posterior areas.

The treatment was planned to correct the posterior crossbite, associated with the protocol for Class III with selfligation fixed orthodontics for dental compensation in the maxilla and mandible. To achieve the first objective, MARPE EX was planned with an $11 \mathrm{~mm}$ opening. Have been added hooks on the molar bands for the use of Class III elastic, and a cantilever for vestibularization of the 23 palatinized element. The expander was cemented and miniscrews were installed according to the technique mentioned in the previous case, including the drills that were used, anesthesia and analgesic indication. After viewing the tomography, the distal areas of the 1st premolar and 1st molar were selected to receive the orthodontic screws (Figure 14).

Figure 13: Panoramic radiography with periapicals and initial teleradiographys.

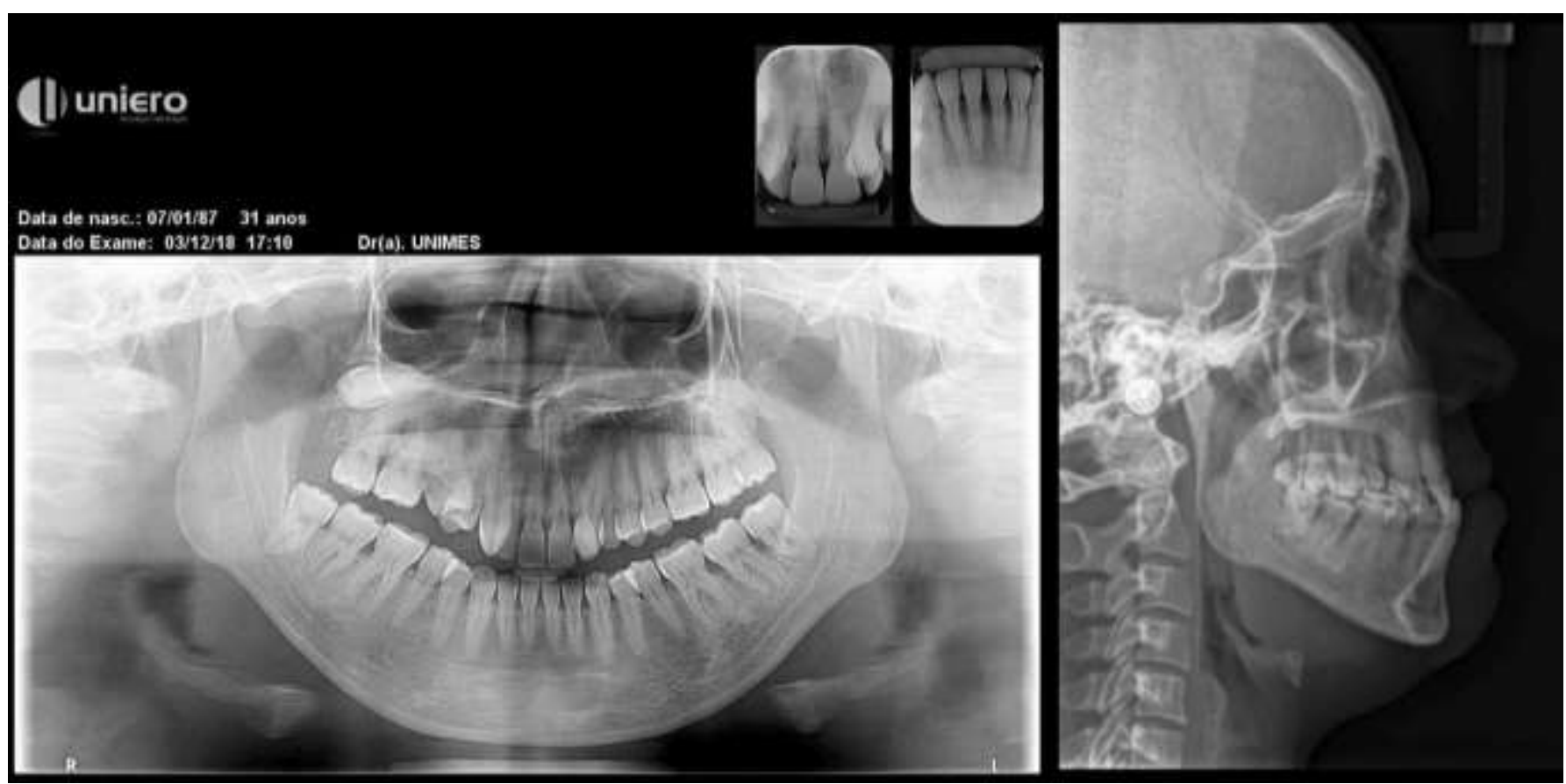

Source: Authors 
Figure 14: CBCT of palate (stage D); sagittal view indicating bone thickness, and axial view of the teeth with selection of the areas that cross the 1st premolars and 1st molars. In coronal view, the measurement of cortical bone and mucosa to select the miniscrews.

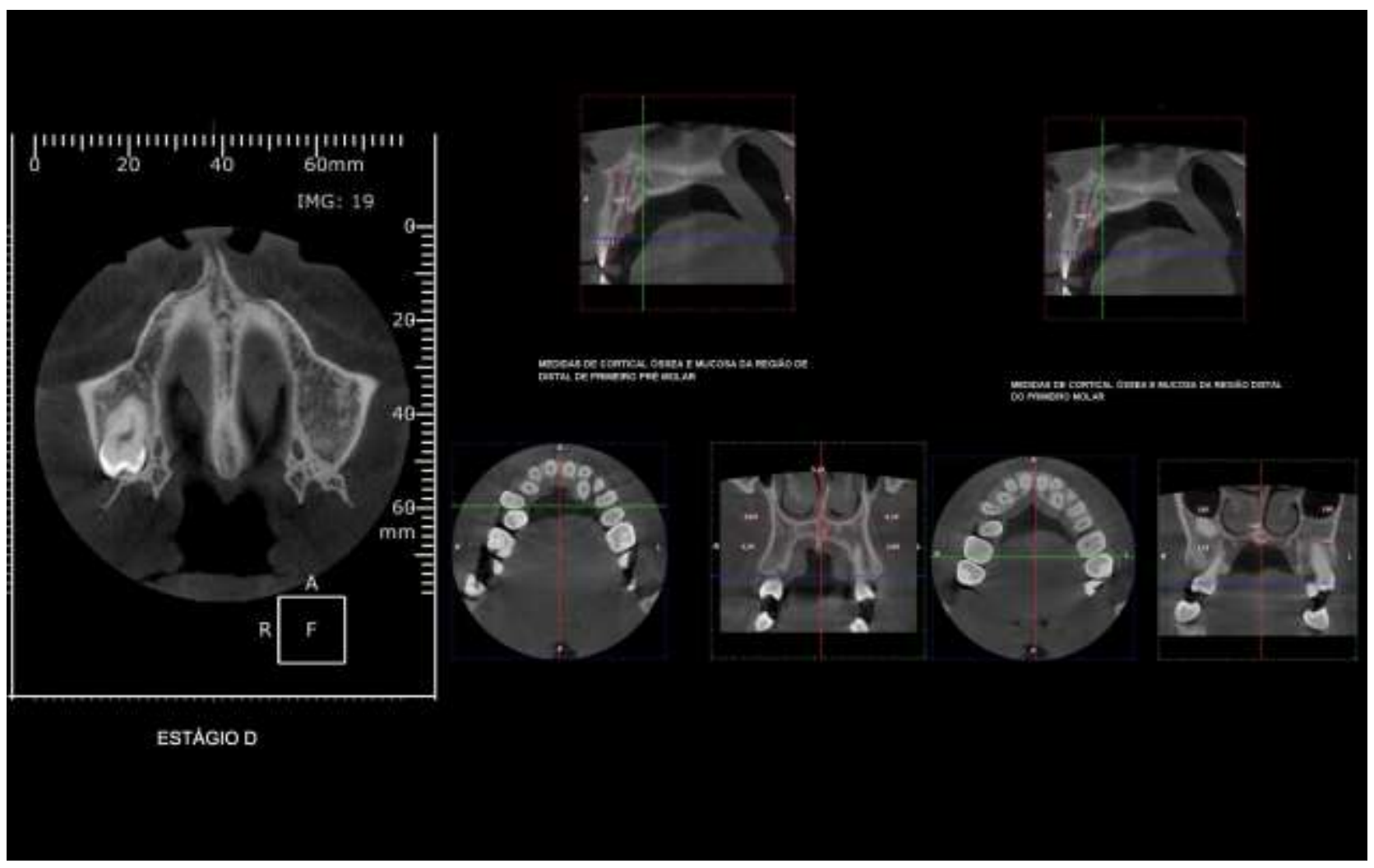

Source: Authors.

Orthodontic screws for MARPE of the PecLab ${ }^{\circledR}$ brand were installed, 02 units for the anterior region (MARPE 1.8 mm x 7 active tip x $8 \mathrm{~mm}$ transmucosal profile) and 02 posterior ones (MARPE $1.8 \mathrm{~mm}$ x $7 \mathrm{~mm} \times 4 \mathrm{~mm}$ ), torqued in $35 \mathrm{~N} . \mathrm{cm}$.

A two activations per day protocol was established. In consultation after 10 days, the patient complained about the difficulty of cleaning the devices, but she did not report pain or discomfort. There was a very slight interincisive diastema and evident vestibularization of the banded molars. To study this complication, a new CBCT exam was requested. In the anterior region, the site that reached the greatest expression of expansion, $2.6 \mathrm{~mm}$ were measured in the buccal cortex, decreasing towards the nasal cortex $(1.8 \mathrm{~mm})$, in coronal section. However, in the posterior areas, the maximum distance between the sutures did not exceed $1.0 \mathrm{~mm}$ (Figure 15). Clinically, the crossbite was maintained.

As a result, corticopunctions of 2 to $5 \mathrm{~mm}$ deep in the parasutural cortex were performed and a more careful approach was initiated, with an activation per day for another 20 days, after which, the interincisive diastema was increased and the bite posterior cross correction was found (Table 01), after which, the interincisive diastema was enlarged and posterior crossbite correction was found. 
Research, Society and Development, v. 10, n. 11, e503101119480, 2021

(CC BY 4.0) | ISSN 2525-3409 | DOI: http://dx.doi.org/10.33448/rsd-v10i11.19480

Figure 15: Intermediate CBCT indicating sutural opening still at very modest levels.

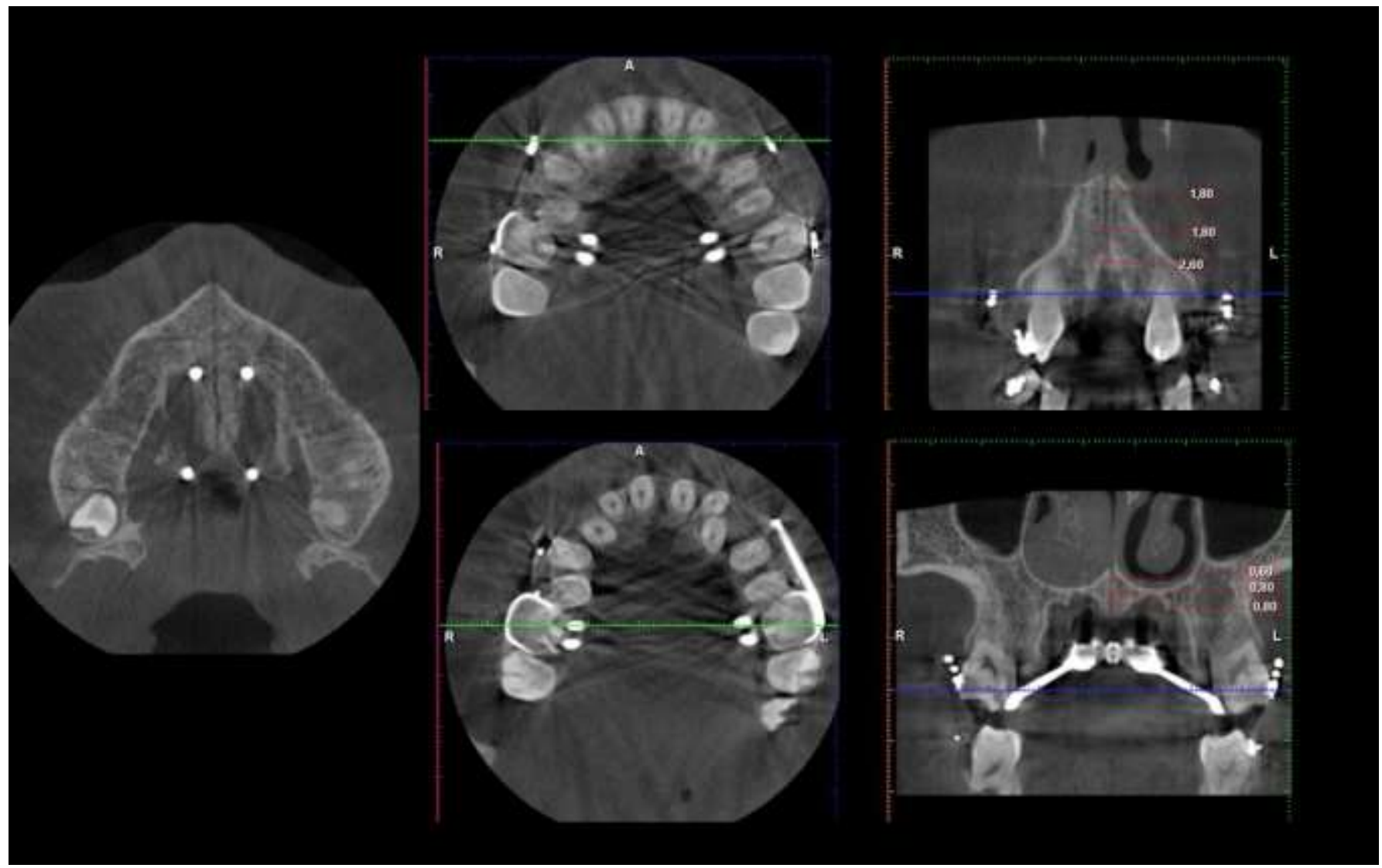

Source: Authors.

Table 1: Quantity, activation period and turning in millimeters of MARPE devices in the reported cases.

\begin{tabular}{|c|c|c|c|c|}
\hline Patient & Orientation & Activations & Period & Opening MARPE \\
\hline \multirow{4}{*}{$\begin{array}{l}\text { Pacient } 01 \\
\text { Adolescent }\end{array}$} & $\mathbf{1}^{\mathrm{a}}$ orientation & 01/day & 14 days & $3,5 \mathrm{~mm}$ \\
\hline & $2^{\mathrm{a}}$ orientation & 04/day & 1 day & $1,0 \mathrm{~mm}$ \\
\hline & $3^{a}$ orientation & 02/day & 10 days & $5,0 \mathrm{~mm}$ \\
\hline & TOTAL & 38 activations & 25 days & $9,5 \mathrm{~mm}$ \\
\hline \multirow{3}{*}{$\begin{array}{c}\text { Pacient } 02 \\
\text { Adult }\end{array}$} & $1^{a}$ orientação & 02/day & 10 days & $5,0 \mathrm{~mm}$ \\
\hline & $2^{\mathrm{a}}$ orientação & 01/day & 20 days & $5,0 \mathrm{~mm}$ \\
\hline & TOTAL & 40 activations & 30 days & $10 \mathrm{~mm}$ \\
\hline
\end{tabular}

Source: Authors.

New CT scans revealed a more uniform maxillary disjunction in the axial direction $(5.4 \mathrm{~mm}$ in the most anterior area and $3.2 \mathrm{~mm}$ posteriorly). In the coronal section, it was possible to detect a more parallel opening between the nasal and buccal cortexes, reaching up to $6.2 \mathrm{~mm}$ of separation. In an area corresponding to the fixation of the posterior screws, $3.7 \mathrm{~mm}$ were measured (Figure 16). The vestibular inclination of the 1st molars was not aggravated and was maintained without cortical involvement. 
Figure 16: Final CBCT indicating adequate disjunction of the midpalatal suture in (A) coronal and (B) axial views.

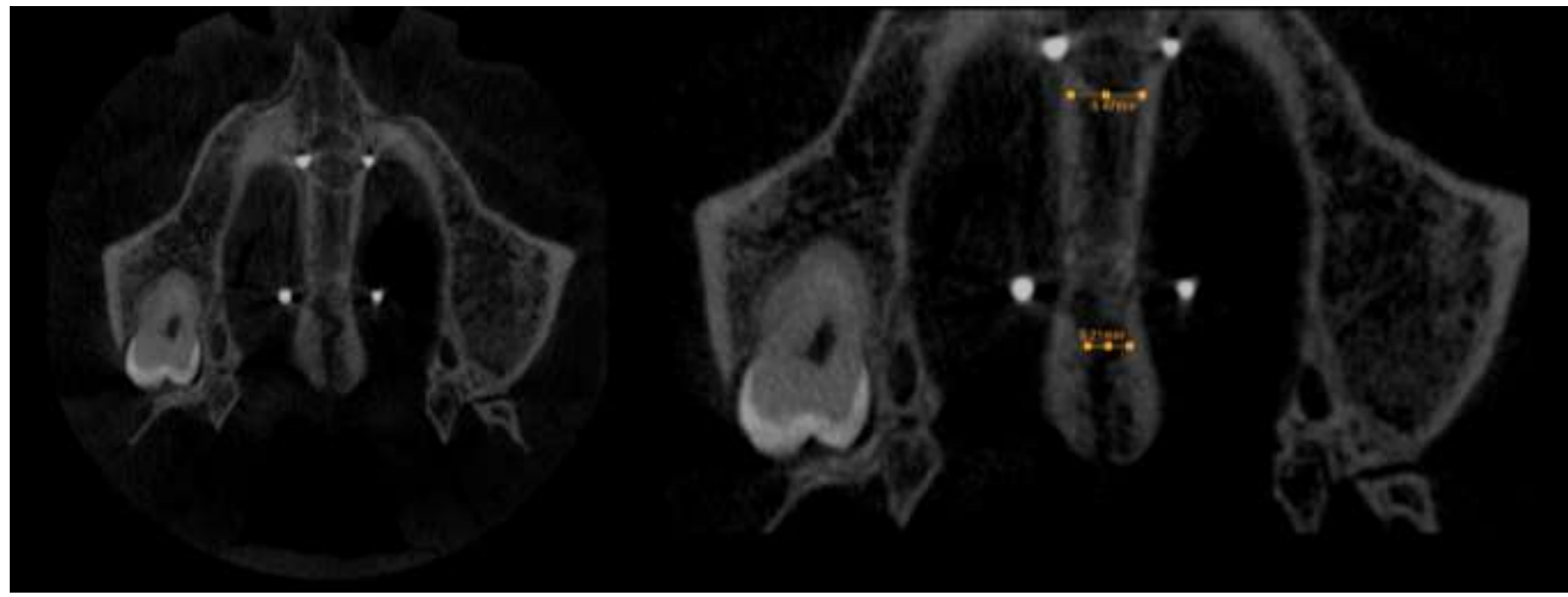

Source: Authors.

As the number of expansions was not expressed at a biological level and there was a molar inclination, it was necessary to compare the tomographic sections to confirm the suspicion of movement of the posterior miniscrews through the bone. The comparison between the intermediate and final CBCT indicated vestibular inclination of the posterior screws (Figure 17). This was checked because the initial distance between the miniscrews was of $6 \mathrm{~mm}$ and $5 \mathrm{~mm}$ were activated; in the intermediate image, almost $11 \mathrm{~mm}$ were observed, indicating that the failure in the disjunction probably occurred due to the displacement of the miniscrews through the bone. With the second series of activations, that were more restrained, it was possible to recover the function of MARPE and expand bone separation, as the inter-screw distance increased by the same amount as skeletal rupture.

Simultaneously with MARPE activations, was installed fixed braces, initially inferior, from 37 to 47 (with the extractions of elements 38 and 48), to initiate dentoalveolar distalization in the mandible by elastic action in a Class III vector, joining the welded hook to the bands from MARPE to the lower canines. The installed brackets were self-ligated .022" (Easy Clip/Aditek®) in the Moderna Orto Class III \& Open Bite prescription (Quintela, 2019). In the round CuNiTi (nitinol alloy with $6 \%$ copper added) wires at $27^{\circ}$, the elastic that was used for 24 hours per day had a diameter of 5/16" (light), and in the rectangular wires, the same diameter was used, with medium strength. The elastic chains anchored in the MARPE cantilever brought the element 23 closer to the arch, after the extraction of 63. Limited by the molars anchored to MARPE, the other elements lined up for vestibular, like an omega effect, correcting the anterior crossbite. Figure 18 demonstrate the progression of the simultaneous treatment. 
Research, Society and Development, v. 10, n. 11, e503101119480, 2021

(CC BY 4.0) | ISSN 2525-3409 | DOI: http://dx.doi.org/10.33448/rsd-v10i11.19480

Figure 17: Distance between the posterior miniscrews after the first $(10.8 \mathrm{~mm})$ and second $(13.8 \mathrm{~mm})$ series of activations, seen in coronal section of the intermediate and final CBCT.

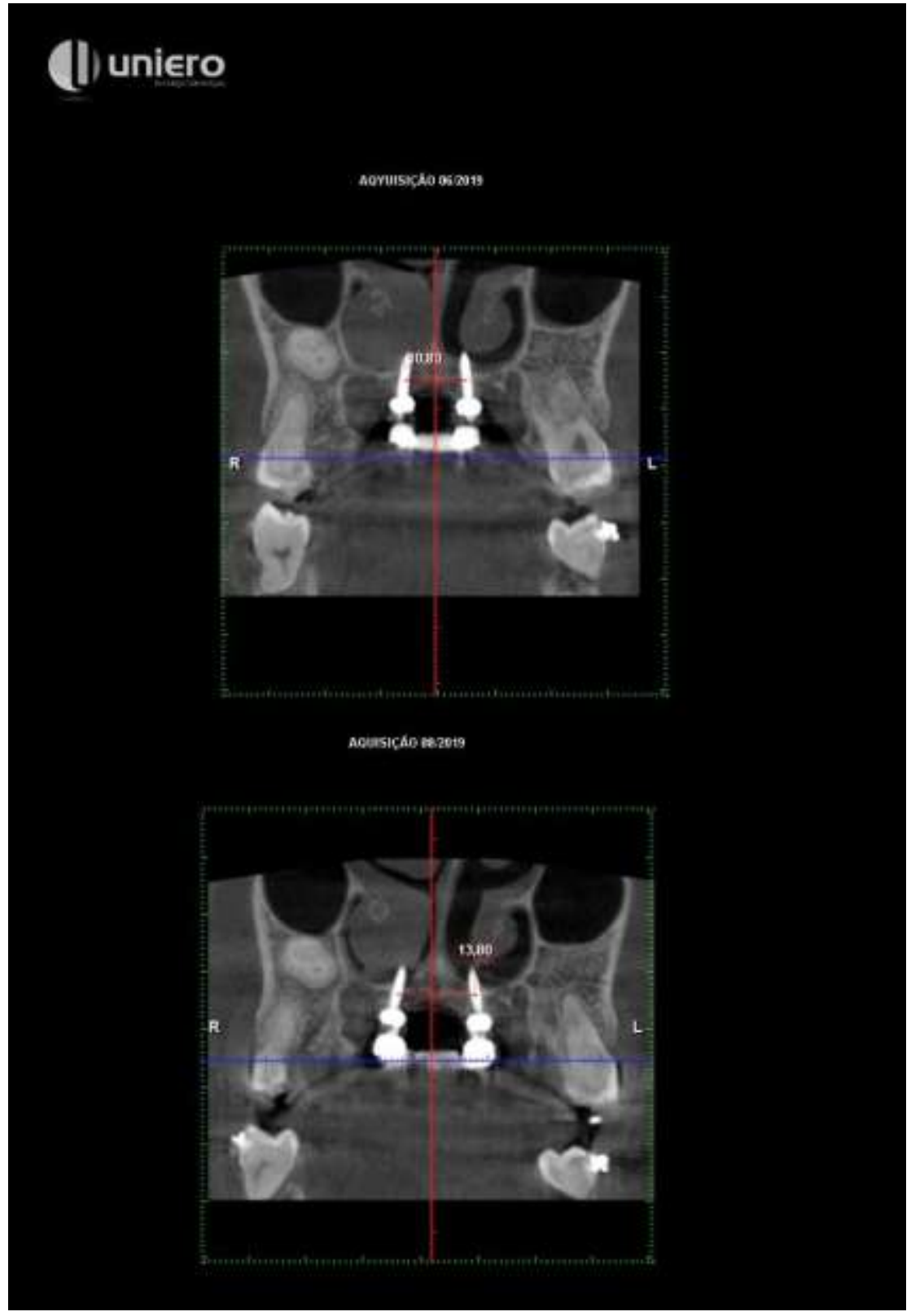

Source: Authors.

In the 3rd month, the bars and bands that connect the expander screw to the 1 st molars were removed to include them in the maxillary orthodontic arch, aiming to mesialize it through the elastic action to be maintained, while the orthodontic arches gradually promoted transverse dentoalveolar remodeling (Figure 19). New panoramic radiography and teleradiography were taken (Figure 20). 
Research, Society and Development, v. 10, n. 11, e503101119480, 2021

(CC BY 4.0) | ISSN 2525-3409 | DOI: http://dx.doi.org/10.33448/rsd-v10i11.19480

Figures 18: (A) (B) (C). Evolution of fixed self-ligation orthodontic treatment, simultaneously to MARPE.

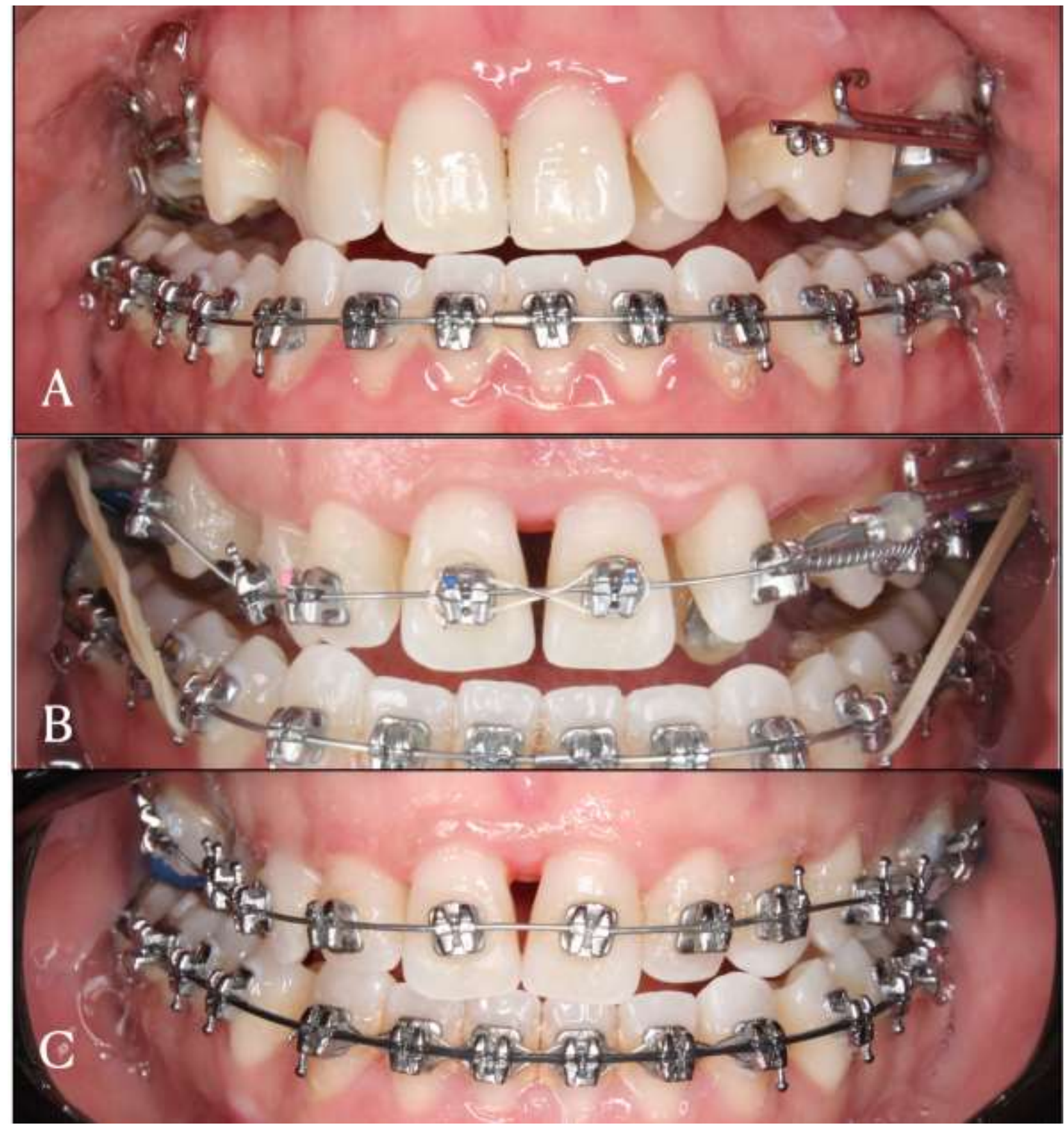

Source: Authors. 
Research, Society and Development, v. 10, n. 11, e503101119480, 2021

(CC BY 4.0) | ISSN 2525-3409 | DOI: http://dx.doi.org/10.33448/rsd-v10i11.19480

Figure 19: MARPE without bands and result of orthodontic-orthopedic treatment to correct the transverse discrepancy of the maxilla.

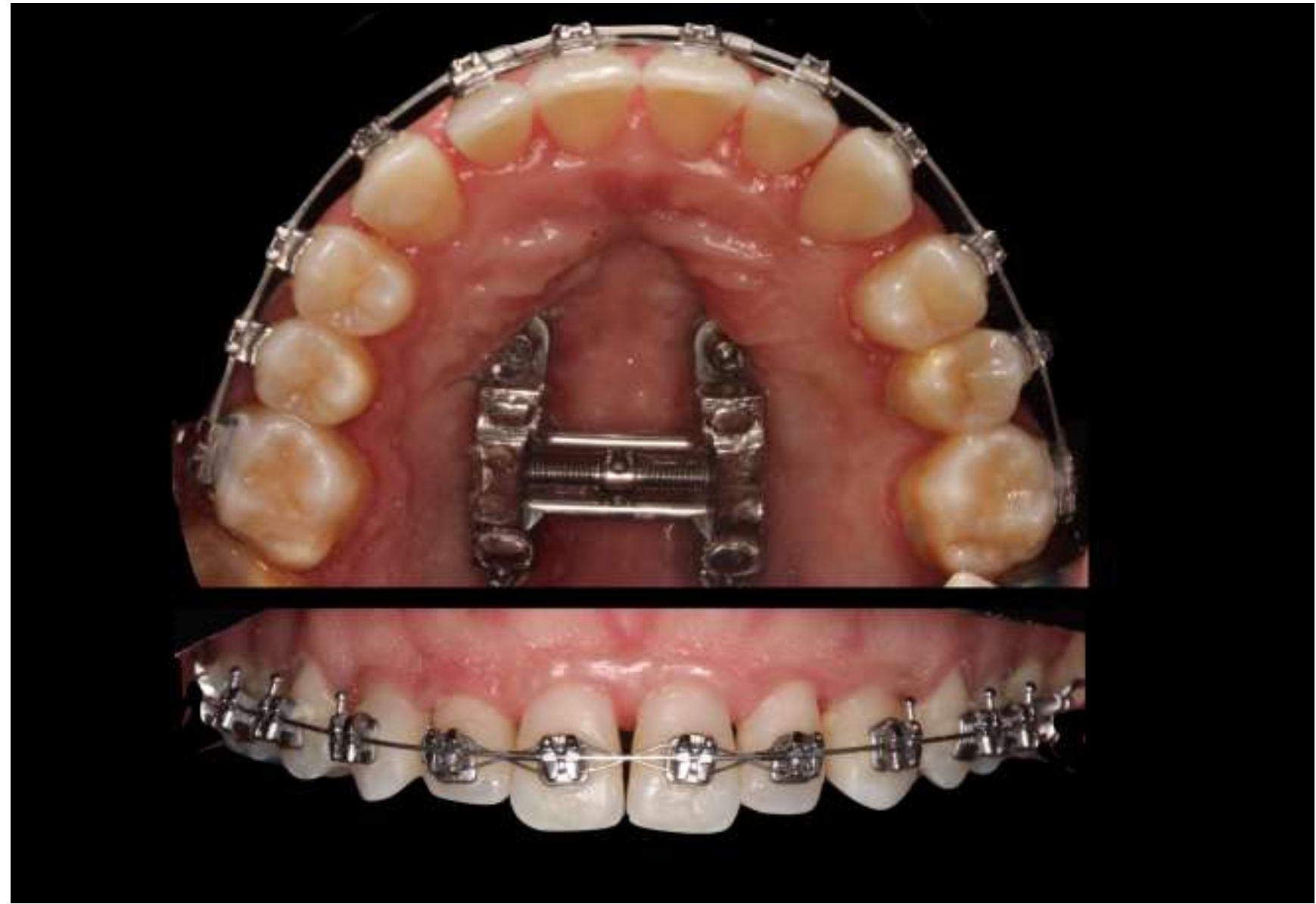

Source: Authors.

Figures 20: Final panoramic radiography (A) and teleradiography (B).

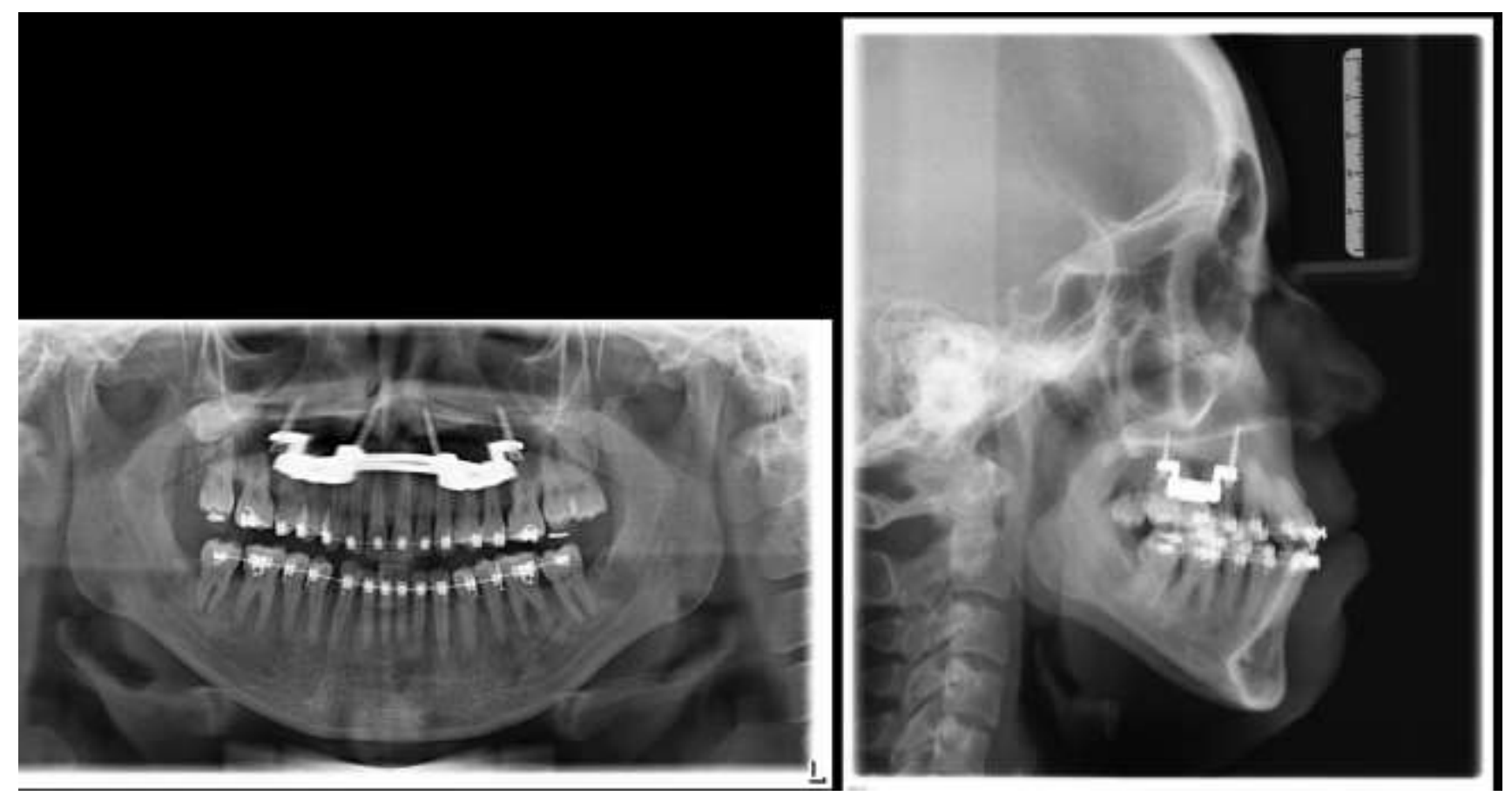

Source: Authors. 


\section{Discussion}

MARPE was developed to avoid unwanted dental effects and obtain "pure" skeletal results in patients at the end of their growth or adults who are reluctant to the surgical procedure (Suzuki et al., 2016).

In both patients, the MARPE was chosen because it allows the accommodation of the miniscrew guides close to the palate mucosa, while the device's expansion vise is suspended. In this type of MARPE, vertical sliding extensions in an "L" shape, individually adjustable, promote better positioning of the piece on an atresic and/or asymmetrical palate.

It is already known that the progression of sutural fusion results in a gradual increase in the rigidity of the facial skeleton by the Grünheid et al. (2017) and Angelieri et al. (2017), and the predictions of success or failure of conventional RME can be directly related to this process (Rossi et al., 2009). For this reason, surgically assisted rapid palatal expansion (SARPE) has been a treatment option to overcome biomechanical limitations.

In the case reports shown in this article, the maturation of the palatal suture was verified using already validated methods that defined fusion stages from $\mathrm{A}$ to $\mathrm{E}$. In the adolescent patient, CBCT seemed to indicate stage $\mathrm{C}$ as the cut appearance of the high-density suture line was verified, indicating interdigitation. In the adult patient, there was already complete fusion in the palatine bone, with no evidence of continuity of the median suture after the transverse palatal suture, indicating Angelieri's stage D.

The choice of MARPE in the adolescent (patient 01) was due to a safety criterion for RME, in which conventional fixed expanders are used only during childhood, when it is known that the desired orthopedic effect is inevitable. From adolescence onwards, the success of the disjunction becomes unpredictable (Silva Filho et al., 2013) and can produce more undesirable effects as the bone skeleton gets more mature. Even so, many professionals perform conventional RME in adolescents, considering its simplicity and, obviously, its non-invasive characteristics.

In a three-dimensional study on finite elements by Seong et al (2018), it was found that excessive stress can be concentrated on the vestibular cortex with conventional RME, while with MARPE, maximum stress was observed around the miniscrews.

If not treated adequately, maxillary atresia can result in occlusal, speech-language, swallowing, periodontal and gingival problems, as well as joint and muscle function disorders, with functional deviation of the mandible that can progress to asymmetric mandibular growth (Aloufi et al., 2012; McNamara et al, 2015). In addition, post-expansion effects of MARPE treatment can lead to air resistance resulting from the narrowing of the nasal cavity and an increase in nasal cavity and nasopharyngeal volume (Alexander, Schroeder; 2013) what can be an etiological factor of obstructive sleep apnea syndrome (OSAS) (Machado et al., 2018). In the treatment of the adolescent patient, no objective breath test was performed. However, it is worth mentioning the patient's perception of her inspiratory quality, after an effective disjunction with MARPE, including a reduction in tiredness and shortness of breath during regular physical activity. In the study of Garcez et al. (2019) was evaluated changes in inspiratory strength after MARPE, skeletal changes resulted in improvement in nasal and oral flow.

Regarding the adult patient (patient 02), this is a therapeutic proposal that corresponds to the needs of a population that is in a therapeutic limbo. Approximately $30 \%$ of adult orthodontic patients have already been found to have transverse maxillary deficiency related to posterior crossbite. It is known that most adults have midpalatal sutures fused in the palate (stage D) and/or in the maxillary bones (stage E), which would indicate the need for treatment by SARPE (Angelieri et al., 2017). However, in the case reported, MARPE was successful despite the complications that the literature related to its chronological age, the advanced stage of sutural maturation and the deficient bone volume on the palate. In contrast, the expression of the disjunction was lower than that seen in patient 01 and the dental repercussions on the supporting molars are symptoms that suggested that the miniscrews have moved through the thin bone thickness in the patient's posterior palate. 
CBCT confirmed this suspicion by showing a greater distance between miniscrews, unrelated to bone separation. Therefore, the miniscrews "walked on the bone", tearing it, and moving the molars in the buccal direction.

Ideally, the expander body should be placed as posteriorly as possible in patient 02 , aiming at a more parallel opening. However, tomographic planning contraindicated this position due to the thin thickness of the palate in the terminal areas. This limitation certainly had an impact on the "V" suture opening (wider in the anterior region) in the adult patient, as also occurs in conventional RME.

Researchers have expressed concerns about the importance of dealing with the increased resistance of the posterior bones near the palate (Matsuyama et al, 2014; MacGinnis et al., 2014). On the other hand, severe deviated septum and little bone thickness in the palatal region could compromise and even make MARPE's success unviable (André, 2018).

In the experience with the adult patient, realizing that a greater transverse movement of the posterior miniscrews, accompanied by molar buccalization were happening, it was decided to proceed with a modified activation protocol (Brunetto et al., 2017). Although these authors suggested, there are no randomized clinical trials, based on more than 100 patients who were observed for 15 years, that activation can be reduced to once a day after the appearance of the interincisive space, reducing the force on miniscrews and favoring its dissipation over the bone, in accordance with the adoption of measures to work on thin posterior bone. In contrast, MacGinnis et al. (2014) applied the activation protocol that is proposed in the literature of 2/4 activation per day, and ensured that, 1) in ideal terms, there is no tooth displacement during the disjunction with MARPE, and 2) if the palatal suture is fused (Stages D and E of Angelieri), the activation force does not dissipate to the adjacent structures, as the palate would be able to withstand the lateral forces produced by the expanding screw.

However, in patient 02, a possible excess of activation force associated with little bone thickness prevented "pure orthopedic movement", as said Suzuki et al. (2016). Accordingly, the decrease in the amount of daily activation of the expander vise may have been essential to unravel the skeletal bite in this patient, while the action of the self-ligation system has provided alignment, leveling and dentoalveolar remodeling by posterior transversal adaptation.

When comparing the cases, table 02 indicates that, in summary, the adolescent patient needed less time and fewer activations to achieve sufficient opening to correct the posterior crossbite, decreasing one millimeter in the posterior direction, indicating a slightly triangular opening. The adult patient, on the other hand, needed more time and more activations, in addition to more procedures, to achieve an excellent opening, but more triangular and with greater buccal movement of the supporting molars.

Table 2: Measurement of palatal disjunction achieved in different areas in the reported cases.

\begin{tabular}{|l|l|l|}
\hline \multicolumn{2}{|c|}{$\begin{array}{c}\text { Coronal View of CBCT post-activacion MARPE } \\
\text { Anteroposterior direction }\end{array}$} \\
\hline Areas of best disjunction & Pacient 01 (adolescent) & Pacient 02 (adult) \\
\hline Distal of 1st premolars & $4,6 \mathrm{~mm}$ & $6,4 \mathrm{~mm}$ \\
\hline Mesial of 1st molars & $4,0 \mathrm{~mm}$ & $5,4 \mathrm{~mm}$ \\
\hline Distal of 1st molars & $4,2 \mathrm{~mm}$ & $3,7 \mathrm{~mm}$ \\
\hline Distal of 2st molars & $3,6 \mathrm{~mm}$ & $3,2 \mathrm{~mm}$ \\
\hline
\end{tabular}

Source: Authors.

The high sutural bone density limits conservative RME, and certainly imposes difficulties on the success of MARPE, since $50 \%$ of patients in their 30 s have not responded with opening of the midpalatal suture in a recent study by Shin et al (2019). Even so, MARPE represents the opening of a therapeutic path that "goes beyond the limits of Orthodontics" (Gurgel, 2019). 


\section{Conclusion}

In the reported cases, MARPE was successful in correcting transverse maxillary deficiency, with the opening of the midpalatal suture being more expressive in the adolescent than in the adult patient. The use of this device may require clinical versatility to adopt differentiated protocols in relation to chronological age, bone thickness and sutural ossification stage to control side effects that, to a greater or lesser extent, determined therapeutic success.

We recommend that future research be carried out, especially in order to present all new elements that, incorporated into MARPE or its protocol, result in greater capacity for palatal disjunction in advanced stages of suture ossification.

\section{References}

Aloufi, F., Preston, C. \& Zawawi, K. (2012). Changes in the Upper and Lower Pharyngeal Airway Spaces Associated with Rapid Maxillary Expansion. ISRN Dentistry;1-5.

André, C. Análise tomográfica para a técnica MARPE. (2018). Revista Clínica de Ortodontia Dental Press.17(4):50-53.

Angelieri, F., Cevidanes, L., Franchi, L., Gonçalves, J., Benavides, E. \& Mc Namara Jr, J (2013). Midpalatal suture maturation: Classification method for individual assessment before rapid maxillary expansion. American Journal Orthodontic and Dentofacial Orthopedic; 144(5):759-769.

Angelieri, F., Franchi, L., Cevidanes, L., Bueno-Silva, B. \& Mc Namara Jr., J. (2016) Prediction of rapid maxillary expansion by assessing the maturation of the midpalatal suture on cone beam CT. Dental Press Journal Orthodontic; 21(6):115-125.

Angelieri, F., Franchi, L., Cevidanes, L., Gonçalves, J., Nieri, M. \& Wolford L et al. Cone beam computed tomography evaluation of midpalatal suture maturation in adults. Internacional Journal Oral Maxillofacial Surgeous. 2017; 46(12):1557-1561.

Brunetto, D. P., Sant'Anna, E. F., Machado, A. W. \& Moon, W. (2017) Non-surgical treatment of transverse deficiency in adults using microimplant-assisted Rapid Palatal Expansion (MARPE). Dental Press Journal Orthodontic. 22(1):110-25.

Choi, S., Shi, K., Cha. J., Park, Y., \& Lee, K (2016): Nonsurgical miniscrew-assisted rapid maxillary expansion results in acceptable stability in young adults. Angle Orthodontic. 86(5):713-720.

Garcez, A., Suzuki, S., Storto, C., Cusmanich, K., Elkenawy, I. \& Moon, W. (2019). Effects of maxillary skeletal expansion on respiratory function and sport performance in a para-athlete - A case report. Physical Therapy Sport. 36:70-77.

Grünheid, T., Larson, C., \& Larson, B. (2017): Midpalatal suture density ratio: A novel predictor of skeletal response to rapid maxillary expansion. American Journal Orthodontic and Dentofacial Orthopedic; 151(2):267-276.

Gurgel, J.A.: Marpe: Expandindo os limites da Ortodontia. Maringá: Editora Dental Press, 2019.

Korbmacher, H., Schilling, A., Püschel, K., Amling, M. \& Kahl-Nieke, B (2007). Age-dependent Three-dimensional Microcomputed Tomography Analysis of the Human Midpalatal Suture. Journal of Orofacial Orthopedics / Fortschritte der Kieferorthopädie. 68(5):364-376.

Lee, K.J., Park, Y.C., Park, J.Y. \& Hwang, W.S. (2010): Miniscrew-assisted nonsurgical palatal expansion before orthognathic surgery for a patient with severe mandibular prognathism. American Journal Orthodontic and Dentofacial Orthopedic; 137:830-839.

MacGinnis, M., Chu, H., Youssef, G., Wu, K., Machado, A. \& Moon, W. (2014). The effects of micro-implant assisted rapid palatal expansion (MARPE) on the nasomaxillary complex — a finite element method (FEM) analysis. Prognostic Orthodontic. 15(1).

Machado, A., Crespo, A. \& Pauna, H. (2018). Rapid maxillary expansion in pediatric patients with obstructive sleep apnea: current and future perspectives. Sleep Medicine. 7-8.

Matsuyama, Y., Motoyoshi, M., Tsurumachi, N. \& Shimizu, N. (2014). Effects of palate depth, modified arm shape, and anchor screw on rapid maxillary expansion: a finite element analysis. European Journal Orthodontic. 37(2):188-193.

McNamara Jr., Lione, R., Franchi, L., Angelieri, F., Cevidanes, L. \& Darendeliler, M. et al. (2015). The role of rapid maxillary expansion in the promotion of oral and general health. Prognostic Orthodontic; 16(1)

Nojima, L. I., Nojima, M. C. G, Cunha, A. C., Guss, N. O. \& Sant'Anna, E. F (2018). Mini-implant selection protocol applied to MARPE. Dental Press Journal Orthodontic.; 23(5):93-101.

Rossi, R., Araújo, M. \& Bolognese, A. (2009): Expansão maxilar em adultos e adolescentes com maturação esquelética avançada. Revista Dental Press de Ortodontia e Ortopedia Facial;14(5):43-52.

Seong, E., Choi, S., Kim, H., Yu, H., Park, Y. \& Lee, K. (2018). Evaluation of the effects of miniscrew incorporation in palatal expanders for young adults using finite element analysis. Korean Journal Orthodontic; 48(2):81.

Shin, H., Hwang, C., Lee, K., Choi, Y., Han, S. \& Yu, H. (2019). Predictors of midpalatal suture expansion by miniscrew-assisted rapid palatal expansion in young adults: A preliminary study. Korean Journal Orthodontic;49(6):360. 
Research, Society and Development, v. 10, n. 11, e503101119480, 2021

(CC BY 4.0) | ISSN 2525-3409 | DOI: http://dx.doi.org/10.33448/rsd-v10i11.19480

Silva Filho, O., Garib, D. \& Lara, T. (2013) Ortodontia interceptiva: protocolo de tratamento em duas fases. Editora Artes Médicas.

Suzuki, S. S., Braga, L. S. F., Fujii, D. N., Moon, W. \& Suzuki, H. (2018). Corticopuncture Facilitated Microimplant-Assisted Rapid Palatal Expansion. Case Reports in Dentistry. 12. https://doi.org/10.1155/2018/1392895.

Suzuki. H., Moon, W., Pevidente, L. H., Suzuki, S. S., Garcez, A. S. \& Consolaro, A. Expansão rápida da maxila assistida com mini-implantes MARPE: em busca de um movimento ortopédico puro. Revista Clínica de Ortodontia Dental Press. 2016;15(2) 100-108. 